\title{
Forsythoside A exerts an anti-endotoxin effect by blocking the LPS/TLR4 signaling pathway and inhibiting Tregs in vitro
}

\author{
XIAO-YAN ZENG ${ }^{1 *}$, WEI YUAN ${ }^{2 *}$, LIN ZHOU $^{3 *}$, SHI-XIU WANG ${ }^{4}$, YONG XIE $^{5}$ and YING-JUN FU ${ }^{1}$ \\ ${ }^{1}$ Department of Pharmaceutical Sciences, School of Medicine, Nanchang University, Nanchang, Jiangxi 330006; \\ ${ }^{2}$ Department of Pharmacy, The Third Affiliated Hospital of Xinxiang Medical University, Xinxiang, Henan 453000; \\ ${ }^{3}$ Department of Pharmacy, The Fourth Affiliated Hospital of Nanchang University, Nanchang, Jiangxi 330003; \\ ${ }^{4}$ Department of Pharmacy, The 260th Hospital of Chinese People's Liberation Army, Shijiazhuang, Hebei 050041; \\ ${ }^{5}$ Department of Gastroenterology, The First Affiliated Hospital of Nanchang University, Nanchang, Jiangxi 330006, P.R. China
}

Received February 16, 2016; Accepted May 8, 2017

DOI: $10.3892 / \mathrm{ijmm} .2017 .2990$

\begin{abstract}
Endotoxins, also referred to as lipopolysaccharides (LPS), are powerful immunostimulators involved in a number of severe diseases. Forsythoside A (FTA), a monomer of phenethyl alcohol glycosides extracted from Forsythia suspensa, has been shown to possess anti-bacterial and immunomodulatory properties. However, it is currently not known whether FTA can counter the adverse effects of endotoxins. We investigated the effect of FTA on LPS-stimulated RAW264.7 cells and primary lymphocytes to determine its molecular mechanism of action. RAW264.7 cells and primary lymphocytes were incubated with or without LPS $(100 \mathrm{ng} / \mathrm{ml})$ in the presence or absence of FTA or polymyxin B. We found that FTA increased the viability of LPS-treated RAW264.7 cells and primary lymphocytes suggesting that FTA effectively counters the adverse effects of endotoxins. FTA decreased the percentage of regulatory $\mathrm{T}$ cells (Tregs) and inhibited the
\end{abstract}

Correspondence to: Dr Yong Xie, Department of Gastroenterology, The First Affiliated Hospital of Nanchang University, 17 YongWai-Zheng Street, Dong-Hu, Nanchang, Jiangxi 330006, P.R. China E-mail: xieyong_med@163.com

Dr Ying-Jun Fu, Department of Pharmaceutical Sciences, School of Medicine, Nanchang University, 461 Ba-Yi Road, Nanchang, Jiangxi 330006, P.R. China

E-mail: fuyingjun123@126.com

"Contributed equally

Abbreviations: ALI, acute lung injury; DMEM, Dulbecco's modified Eagle's medium; FTA, forsythoside A; FBS, fetal bovine serum; IL, interleukin; LPS, lipopolysaccharides; PAMP, pathogen-associated molecular patterns; NF- $\kappa B$, nuclear factor- $\kappa B$; PAMP, pathogen-associated molecular patterns; PMB, polymyxin $\mathrm{B}$; TCR, T-cell receptor; TLR, Toll-like receptors; TNF, tumor necrosis factor; Tregs, regulatory $\mathrm{T}$ cells

Key words: forsythoside A, anti-endotoxin, lipopolysaccharides, Toll-like receptor 4 , regulatory $\mathrm{T}$ cells
TLR4/MyD88/NF- $\mathrm{BB}$ signaling pathway, downregulating Foxp3, IL-10 and TGF- $\beta 1$, molecules involved in the immunosuppressive function of Tregs. These findings elucidate the molecular mechanism underlying the anti-endotoxin effects of FTA and suggest its use as a new treatment for LPS-induced diseases.

\section{Introduction}

Endotoxins, also referred to as lipopolysaccharides (LPS), are considered as the most powerful stimulators of the immune system and measurement of their levels is considered to be a useful specific indicator of infection by Gram-negative bacteria in diverse eukaryotes, ranging from insects to humans (1). LPS are present in many liquids or many biomaterials, even if the material is sterile (2), and can elicit a biological effect even at extremely dilute concentrations (3). High levels of endotoxins in the blood can cause various disease status, including systemic inflammatory response syndrome, sepsis, severe shock, multiple organ dysfunction syndrome, multiple organ failure and even death (4). Despite the recognized potential for causing harm, there is currently no effective method available for treating LPS-induced diseases.

LPS and other microbial products are recognized by the innate immune system of the body through the action of Tolllike receptors (TLRs), leading to activation of the downstream signal transduction pathways and stimulation of a range of immune responses $(5,6)$. TLR4 is the first TLR discovered in humans $(7,8)$ and is capable of identifying bacterial LPS. LPS binding to TLR4 triggers myeloid differentiation through primary response gene-88 (MyD88)-independent pathways (9), leading to subsequent activation of nuclear transcription factor

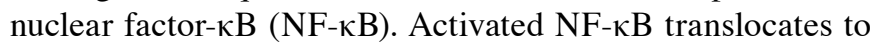
the nucleus and mediates the transcription of a number of genes (10). Studies have shown that NF- $\kappa B$ can effectively induce the expression of genes encoding inflammatory mediators and stimulate their release from cells (11). Therefore, treatments aimed at inhibiting the TLR4/MyD88/NF- $\kappa B$ signaling pathway may have potential therapeutic advantages over currently available approaches for managing the effects of LPS. However, the inhibition of the TLR4/MyD88/NF-кB 
signaling pathway may also damage the anti-microbial immunity of the host.

Upon encountering pathogens and environmental insults, recruitment and activation of effector $\mathrm{T}$ and $\mathrm{B}$ cells and, importantly, regulatory $\mathrm{T}$ cells (Tregs) contribute to the maintenance of immune homeostasis, prevention of autoimmunity and moderation of the inflammatory response (12). Tregs are a functionally mature subpopulation of T cells, characterized as $\mathrm{CD} 4^{+} / \mathrm{CD} 25^{+} / \mathrm{Foxp}^{+}$. Tregs are generated in the thymus or by differentiation from peripheral $\mathrm{CD} 4^{+} \mathrm{CD} 25^{-}$native $\mathrm{T}$ cells (13). Tregs play key roles in the maintenance of immunologic selftolerance and negative control of a number of physiological and pathological immune responses, with growing recognition of the clinical importance of Tregs. Since TLR4 is expressed on Tregs, LPS may affect their function through stimulation of TLR4. Foxp3 protein is considered to be the most reliable molecular marker of mature Tregs and is involved in the development and function of Tregs. Several mechanisms of Treg-mediated suppression of the immune response have been proposed, including secretion of immunosuppressive cytokines, cell-contact-dependent suppression and functional modification or killing of antigen-presenting cells $(12,14)$, among others. Tregs are unresponsive to T cell receptor (TCR) stimulation, express transforming growth factor- $\beta$ (TGF- $\beta$ ) and interleukin-10 (IL-10), inhibit normal T cell proliferation, and suppress $\mathrm{CD}^{+}{ }^{+}$expansion in vivo.

Many researchers are engaged in identifying novel active compounds from plants for the treatment of human diseases. Qinghaosu (artemisinin) used as an antimalarial drug is well known (15). Compound Danshen dropping pill has been widely used for cardiovascular disease in China and some Asia countries (16). Moreover, numerous traditional medicines have anti-endotoxin effects such as andrographolide, resveratrol, praeruptorin and osthole (17-20). Forsythoside A (FTA) (Fig. 1) is a pharmacologically active monomer of benzene glycoside extract from the Forsythia suspensa plant. It was reported to possess anti-bacterial, anti-viral, anti-oxidant, and immunomodulatory properties (21). Recent studies have shown that forsythoside can significantly enhance macrophage phagocytosis and reduce tumor necrosis factor- $\alpha$ (TNF- $\alpha$ ) secretion in LPS-stimulated RAW264.7 cells, thereby suggesting that it can elicit various anti-LPS effects (22). However, the precise anti-endotoxin effects of FTA have not been elucidated to date.

In the present study, we investigated the ability of FTA to suppress the effects of LPS in vitro. Furthermore, we evaluated whether the effects involve the LPS/TLR4/MyD88/NF- $\mathrm{B}$ signaling pathway and inhibition of Tregs.

\section{Materials and methods}

Reagents. Bacterial LPS (Escherichia coli: 055:B5, used at $100 \mathrm{ng} / \mathrm{ml})$ and polymyxin B (PMB, used at $10 \mu \mathrm{g} / \mathrm{ml})$ were obtained from Sigma (St. Louis, MO, USA). FTA solution (>98\% HPLC purity; cat. no. L28-110506; Jiangxi Tiangong Herbal Technology Co., Ltd.) was prepared at a concentration of $1 \mathrm{mg} / \mathrm{ml}$ in sterile water. The materials under study were endotoxin-free.

Animals. Male BALB/c mice $(18 \pm 2 \mathrm{~g}, 6-8$ weeks old) were purchased from Hunan Slack King Laboratory

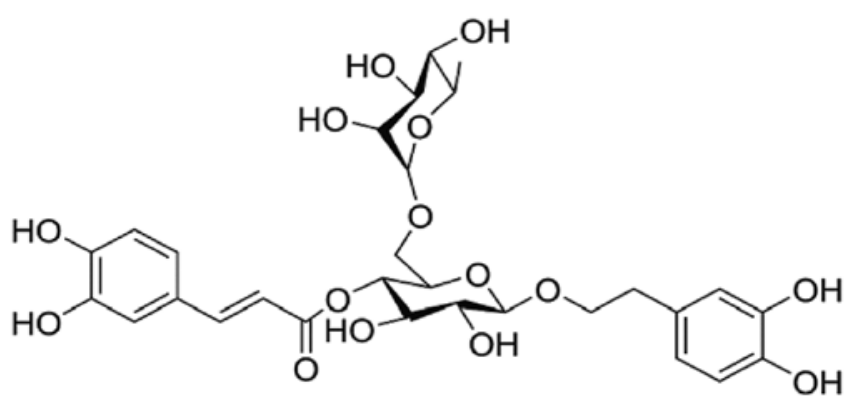

Figure 1. Chemical structure of forsythoside A (FTA).

Animal Co., Ltd. The mice were housed in a room maintained at $24 \pm 1^{\circ} \mathrm{C}$ with $40-80 \%$ humidity. All animals received food and water ad libitum. Mice were housed for 2-3 days to adapt to the environment before the experiments. The experimental procedures were approved by the Commission of Nanchang University for Ethics of Experiments on Animals and were conducted in accordance with international standards. All surgery was performed under chloral hydrate anesthesia, and all efforts were made to minimize animal suffering.

Leukocyte isolation. Two to four spleens were converted into single-cell suspensions by squeezing through a $74-\mu \mathrm{m}$ nylon net with the rough end of a 5-ml syringe plunger. The singlecell suspensions were filtered using a $37-\mu \mathrm{m}$ nylon net. Then, the cells were spun down in a $15-\mathrm{ml}$ Falcon tube $(10 \mathrm{~min}$, $1,500 \mathrm{rpm}$ ) and the supernatant was discarded. The pellets were resuspended in $1 \mathrm{ml}$ of warm RPMI-1640 medium, layered above $2 \mathrm{ml}$ of lymphocyte separation medium (LSM; Solarbio, Beijing, China) and centrifuged for $20 \mathrm{~min}$ at $20^{\circ} \mathrm{C}$ at 2,000 rpm. The top layer of clear plasma was aspirated to within 2-3 $\mathrm{mm}$ above the lymphocyte layer and discarded. Next, the lymphocyte layer were aspirated and diluted with warm RPMI-1640 medium into a new centrifuge tube and centrifuged for $10 \mathrm{~min}$ at $1,000 \mathrm{rpm}$ twice. Finally, the cells were resuspended in warm RPMI-1640 medium.

Cell culture and cell groups. RAW264.7 cells (Department of Gastroenterology, Jiangxi, China) were maintained in Dulbecco's modified Eagle's medium (DMEM) containing $10 \%$ heat-inactivated fetal bovine serum (FBS) and antibiotics (100 U/ml of penicillin, $100 \mathrm{mg} / \mathrm{ml}$ of streptomycin). RAW264.7 cells were divided into 6 groups: i) control group, incubated without any treatment; ii) LPS group, incubated with LPS (100 ng/ml) for $12 \mathrm{~h}$; (iii-v) FTA groups: preconditioned by incubation with FTA $(20,80$ or $320 \mu \mathrm{g} / \mathrm{ml})$ for $2 \mathrm{~h}$ before the addition of LPS (100 ng/ml) and incubation for $12 \mathrm{~h}$; vi) $\mathrm{PMB}$ group, preconditioned with $\mathrm{PMB}(10 \mu \mathrm{g} / \mathrm{ml})$ before the addition of LPS (100 ng/ml) and incubation for $12 \mathrm{~h}$.

Isolated mouse lymphocytes were suspended in $10 \% \mathrm{FBS}$ and RPMI-1640 medium at a concentration of $1 \times 10^{6}$ cells $/ \mathrm{ml}$ and plated in 6-well multiplates prior to the addition of ConA (final concentration, $5 \mu \mathrm{g} / \mathrm{ml}$ ) and IL-2 (final concentration, $100 \mathrm{ng} / \mathrm{ml}$ ) (both from Sigma). Cell cultures were maintained at $37^{\circ} \mathrm{C}$ in a humidified atmosphere of $5 \% \mathrm{CO}_{2}$ and $95 \%$ air. Lymphocytes were divided into 6 groups and treated as 
described above for RAW264.7 cells, except with longer (48 h) LPS stimulation.

Cell viability assay. Cell viability was assessed using the MTT assay. All cells were cultured in 96-well plates in an incubator at $37^{\circ} \mathrm{C}$ and $5 \% \mathrm{CO}_{2}$, with RAW264.7 cells cultured at a density of $10^{5}$ cells/well for $12 \mathrm{~h}$ and lymphocytes cultured at $10^{6}$ cells/well for $2 \mathrm{~h}$. Cells were washed with fresh medium prior to incubation with a range of FTA concentrations $(20,80$ or $320 \mu \mathrm{g} / \mathrm{ml})$ or PMB $(10 \mu \mathrm{g} / \mathrm{ml})$ for $2 \mathrm{~h}$. The medium was discarded and LPS (100 ng/ml) was added to the incubation mixture. RAW264.7 cells and lymphocytes were incubated with LPS for 12 and $48 \mathrm{~h}$, respectively. Cells were washed and $20 \mu \mathrm{l}$ of MTT $(5 \mathrm{mg} / \mathrm{ml})$ was added, followed by incubation for $4 \mathrm{~h}$. Finally, DMSO $(150 \mu \mathrm{l})$ was added to solubilize the formazan salt formed and the amount of formazan salt was determined by measuring the absorbance at $570 \mathrm{~nm}$ using a microplate reader (Bio-Rad, Hercules, CA, USA). Data are expressed as means \pm SD from at least 3 independent experiments.

ELISA for quantification of TNF- $\alpha, I L-10$ and TGF- $\beta 1$ levels. Expression of TNF- $\alpha$ in RAW264.7 cell culture supernatants was quantified using a commercially available ELISA kit, according to the manufacturer's instructions (eBioscience, San Diego, CA, USA). IL-10 and TGF- $\beta 1$ levels were determined in supernatants obtained from the lymphocyte culture using ELISA kits (Westang Co., Ltd., Shanghai, China). The absorbance was read at $450 \mathrm{~nm}$ using a microplate reader (Bio-Rad). The levels of cytokines were calculated using standard curves prepared by analyzing a range of concentrations of purified recombinant TNF- $\alpha$, IL-10 and TGF- $\beta 1$.

Flow cytometric analysis. Primary lymphocytes in each group was collected and washed twice with phosphatebuffered saline (PBS) and further divided into the isotype control group and experimental group. Cells in the isotype control group were stained with Armenian hamster IgG isotype control PE-cyanine5, rat IgG1 isotype control PE, and rat IgG2a isotype control FITC (all from eBioscience), while the experimental group was stained with anti-mouse CD3e PE-Cy5, anti-mouse CD4 FITC, and anti-mouse CD25 $\mathrm{PE}$ (eBioscience) at the concentrations recommended by the manufacturer for $15 \mathrm{~min}$ in the dark at room temperature. Red blood cell lysis buffer $(1 \mathrm{ml})$ was added to each sample of collected primary lymphocytes and incubated for $10 \mathrm{~min}$ in the dark at room temperature. Finally, the cells were washed with PBS and fixed with RPMI-1640 medium prior to analysis in a FACSCalibur flow cytometer using CellQuest software (BD Biosciences, San Jose, CA, USA).

Western blotting for TLR4, MyD88, NF- $\kappa B$ and Foxp3. RAW264.7 cells and lymphocytes were plated onto 6 60-mm plastic dishes and incubated as described above. The expression levels of TLR4, NF- $\kappa$ B and MyD88 in RAW264.7 cells and Foxp3 in lymphocytes were determined by western blot analysis, using $\beta$-actin expression as a reference. Briefly, after drug treatment, the cells were lysed with ice-cold RIPA buffer (Solarbio), and the protein content of the lysates was measured using the bicinchoninic acid (BCA) method. Equal amounts of cellular proteins were separated by $10 \%$ sodium dodecyl sulfate-polyacrylamide gel electrophoresis (SDS-PAGE) and transferred to a nitrocellulose filter membrane. After blocking with $5 \%$ non-fat milk powder, the membranes were incubated with respective rabbit anti-mouse polyclonal antibodies [TLR4 (ab13556), MyD88 (ab2068), Foxp3 (ab54501) or $\mathrm{NF}-\kappa \mathrm{B}(\mathrm{ab} 16502)]$ and murine monoclonal antibodies [ $\beta$-actin (ab8226)] (both from Abcam, Cambridge, MA, USA) at $4^{\circ} \mathrm{C}$ overnight. After washing in TBST (3 washes of 10 min each), the membranes were incubated with peroxidase-conjugated Affinipure goat anti-rabbit (ZB-2301) or mouse (ZB-2305) immunoglobulin $\mathrm{G}$ antibodies (ZSGB-BIO, Beijing, China) for $1 \mathrm{~h}$ at room temperature and visualized with enhanced chemiluminescence reagents (Thermo Fisher Scientific, Inc., Waltham, MA, USA) following exposure to X-ray film. The relative band intensity was quantified by Quantity One software v4.62 (Bio-Rad) to determine the protein levels.

Quantitative (real-time) PCR. Using EZN Total RNA Kit II (Omega Bio-Teck, Doraville, GA, USA), the total RNA was extracted from RAW264.7 cells and lymphocytes, according to the maufacturer's instructions. cDNA was produced using PrimeScript RT reagent kit with gDNA Eraser (Takara Biotechnology, Dalian, China). Real-time polymerase chain reaction was performed on an ABI-Prism StepOne using SYBR Premix Ex Taq II (Takara Biotechnology). The primers used were 5'-TTTATTCAGAGCCGTTGG-3' and 5'-AGTTGC CGTTTCTTGTTG-3' for mouse TLR4; 5'-ACTCGCAGTTT GTTGGATG-3' and 5'-ACTCGCAGTTTGTTGGATG-3' for mouse MyD88; 5'-CTCATGATAGTGCCTGTGTCCTCAA-3' and 5'-AGGGCCAGCATAGGTGCAAG-3' for mouse Foxp3; 5'-CATCCGTAAAGACCTCTATGCCAAC-3' and 5'-ATGGA GCCACCGATCCACA-3' for mouse $\beta$-actin. The PCR amplification profiles consisted of denaturation at $95^{\circ} \mathrm{C}$ for $30 \mathrm{sec}$, followed by 40 cycles of denaturation at $95^{\circ} \mathrm{C}$ for $5 \mathrm{sec}$ and annealing at $62^{\circ} \mathrm{C}$ for $34 \mathrm{sec}$. All amplification reactions for each sample were carried out in triplicate, and the relative expression values were normalized to the expression value of mouse $\beta$-actin.

Data processing. Statistical analysis was performed with IBM SPSS Statistics software (version 19.0; SPSS, Inc., Chicago, IL, USA). Data are expressed as mean \pm SEM. The differences between the data sets were assesses by one-way analysis of variance (ANOVA) and Student-Newman-Keuls (SNK)-q test. $\mathrm{P}$-value $<0.05$ was considered to indicate a statisical significant result.

\section{Results}

FTA increases the viability of LPS-treated RAW264.7 cells and lymphocytes. RAW264.7 cells and lymphocytes treated with LPS alone exhibited severe cell damage and reduced cell viability compared to the untreated control cells $(\mathrm{P}<0.01)$ (Fig. 2). Treatment with FTA dose-dependently reduced LPS-induced damage in the RAW264.7 cells and lymphocytes (Fig. 2).

\section{FTA reduces cytokine production}

$T N F-\alpha$. The accumulation of TNF- $\alpha$ was measured to assess the effect of FTA treatment on this proinflammatory cytokine. LPS-treated RAW264.7 cells exhibited markedly increased 

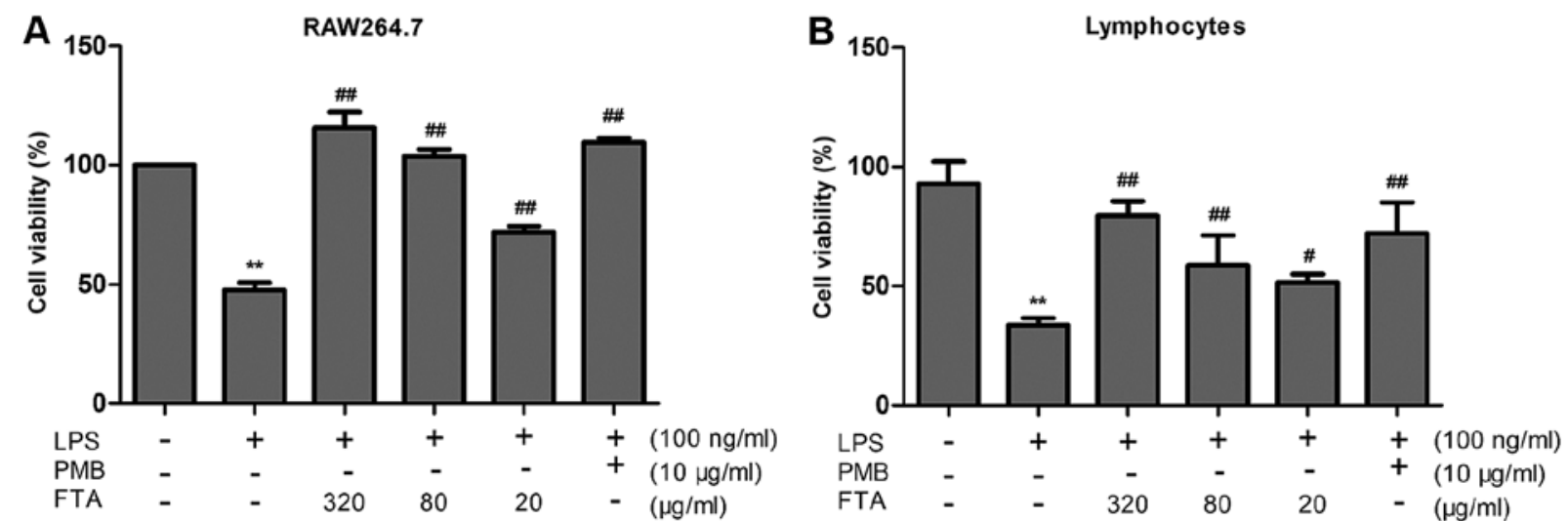

Figure 2. Effect of forsythoside A (FTA) on the viability of cells. RAW264.7 cells (A) and lymphocytes (B) were stimulated with lipopolysaccharide (LPS, $100 \mathrm{ng} / \mathrm{ml}, 12$ or $48 \mathrm{~h}$, respectively) in the absence or presence of pretreatment with polymyxin B (PMB, $10 \mu \mathrm{g} / \mathrm{ml}, 2 \mathrm{~h})$ or FTA $(320,80 \mathrm{and} 20 \mu \mathrm{g} / \mathrm{ml}, 2 \mathrm{~h})$ MTT cell-viability assays were conducted. PMB was used as the positive control. Values are expressed as the mean \pm SEM of six (A) or eight (B) independent experiments. ${ }^{* *} \mathrm{P}<0.01$ vs. the control group; ${ }^{\# \#} \mathrm{P}<0.01$ and ${ }^{\#} \mathrm{P}<0.05$ vs. the LPS-treated group.
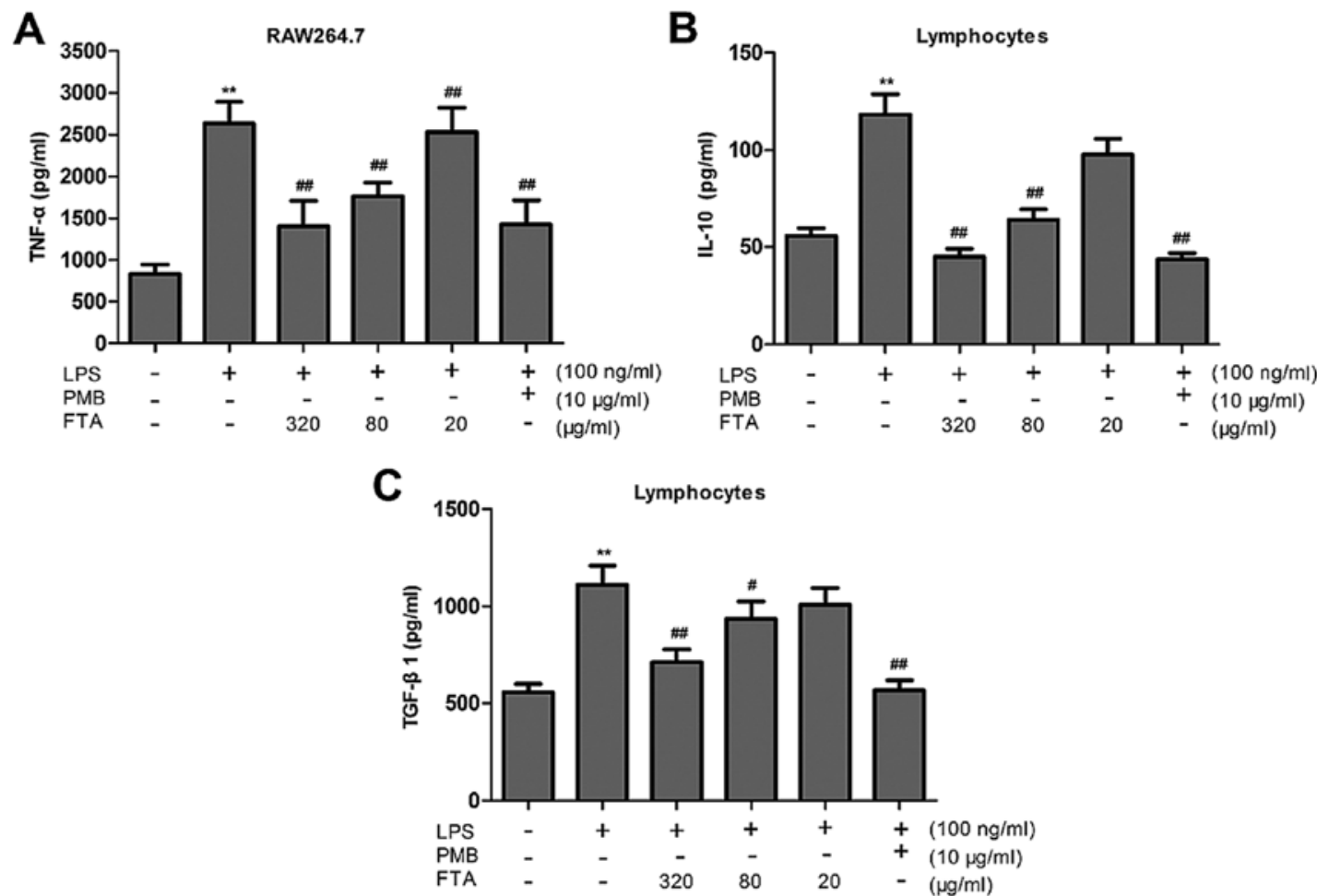

Figure 3. Forsythoside A (FTA) inhibits lipopolysaccharide (LPS)-induced release of cytokines. The levels of TNF- $\alpha$ were measured in RAW264.7 cell culture (A). IL-10 (B) and TGF- $\beta 1$ (C) levels were determined in lymphocyte culture. Values are expressed as the mean \pm SEM of eight (A) or three (B and C) independent experiments. ${ }^{* *} \mathrm{P}<0.01$ and ${ }^{*} \mathrm{P}<0.05$ vs. the control group; ${ }^{\# \#} \mathrm{P}<0.01$ and ${ }^{\#} \mathrm{P}<0.05$ vs. the LPS-treated group.

cytokine production compared to the control group, while FTA treatment significantly inhibited the LPS-induced increase in TNF- $\alpha$ concentration in a dose-dependent manner (Fig. 3A).

$I L-10$ and $T G F-\beta 1$. We examined the effect of FTA on the production of proinflammatory cytokines IL-10 and TGF- $\beta 1$. Lymphocytes were pretreated with FTA for $2 \mathrm{~h}$ and levels of IL-10 and TGF- $\beta 1$ were measured in culture media by ELISA. IL-10 and TGF- $\beta 1$ were found to be upregulated in the LPS-stimulated lymphocytes, with the pretreatment with FTA eliciting suppression of the LPS-induced increase (Fig. 3B and C). These results suggest that the immunomodulatory effect of FTA may be mediated through the inhibition of IL-10 and TGF- $\beta 1$ production.
FTA inhibits LPS-induced activation of TLR4/MyD88/NF- $\kappa B$ signaling. To elucidate the mechanisms underlying the inhibition of LPS-induced production of proinflammatory cytokines, we investigated the expression levels of TLR4, MyD88 and NF- $\kappa$ B protein, and TLR4 and MyD88 mRNA in RAW264.7 cells. LPS binds TLR4, leading to the activation of MyD88-dependent and MyD88-independent signaling pathways. NF- $\kappa \mathrm{B}$ is activated within the MyD88-dependent pathway and has been implicated in the regulation of the TNF- $\alpha$ promoter (23). The expression of proteins involved in the TLR4 signaling pathway was increased in the RAW264.7 cells after LPS administration (Fig. 4). Incubation with FTA 
A
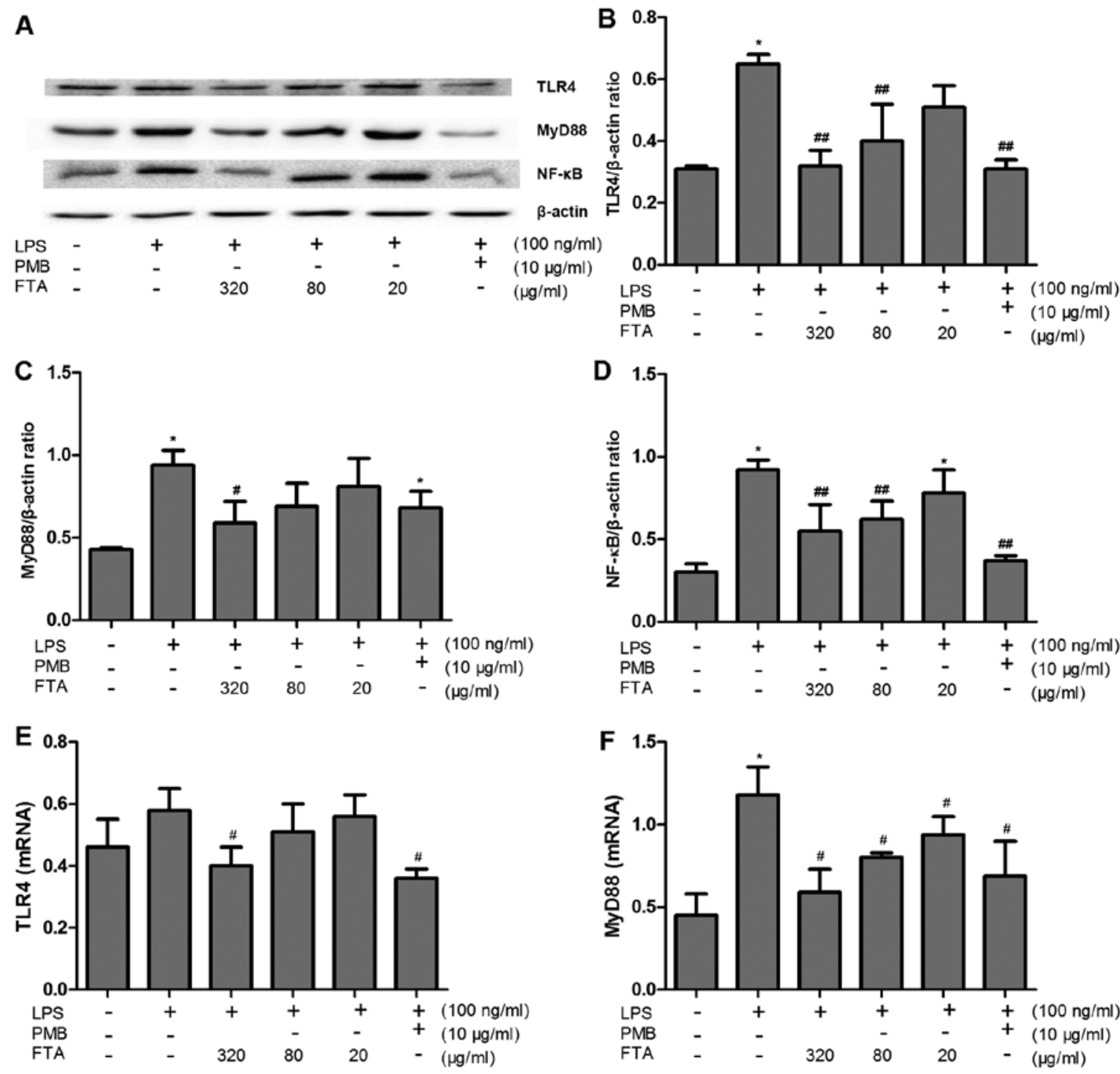

Figure 4. Forsythoside A (FTA) inhibits lipopolysaccharide (LPS)/TLR4 signaling in a dose-dependent manner. RAW264.7 cells were stimulated with LPS $(100 \mathrm{ng} / \mathrm{ml}, 12 \mathrm{~h})$ in the absence or presence of pretreatment polymyxin B (PMB, $10 \mu \mathrm{g} / \mathrm{ml}, 2 \mathrm{~h})$ or FTA $(320,80$ and $20 \mu \mathrm{g} / \mathrm{ml}, 2 \mathrm{~h})$. The expression levels

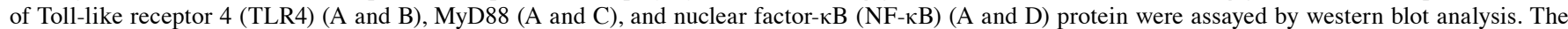
expression levels of TLR4 (E) and MyD88 (F) mRNA were assayed by quantitative PCR. $\beta$-actin was used as a loading control. Values are mean \pm SEM of three independent experiments. ${ }^{* *} \mathrm{P}<0.01$ and ${ }^{~} \mathrm{P}<0.05$ vs. the control group; ${ }^{\# \#} \mathrm{P}<0.01$ and ${ }^{\#} \mathrm{P}<0.05$ vs. the LPS-treated group.

significantly inhibited the effect of LPS in a concentration dependent-manner. These results suggest that FTA inhibits the TLR4 signaling pathway and thereby protects macrophages from LPS stimulation.

\section{FTA decreases the Treg percentage and the expression levels of Foxp 3 protein and $m R N A$}

FTA decreases Treg percentage.LPS induced a marked increase in the relative percentage of $\mathrm{CD} 4^{+} \mathrm{CD} 25^{+} / \mathrm{CD} 4^{+} \mathrm{T}$ lymphocytes $(\mathrm{P}<0.01)$, which was significantly attenuated by treatment with FTA (80 and $320 \mu \mathrm{g} / \mathrm{ml}$ ) (Fig. 5G). FTA treatment decreased LPS-induced changes in the relative percentage of Tregs in a dose dependent manner. These findings are in agreement with the results of flow cytometry (Fig. 5A-F). The in vitro results, therefore, suggest that FTA elicits immunomodulatory effects.

FTA decreases the expression levels of Foxp 3 protein and $m R N A$. The expression levels of Foxp3 protein and mRNA in the LPS-treated cells were markedly increased compared to these levels in the control group $(\mathrm{P}<0.01)$ (Fig. 6). However, FTA treatment significantly decreased levels of Foxp3 protein and mRNA in the LPS-treated cells in a dose-dependent manner $(\mathrm{P}<0.01$ or $\mathrm{P}<0.05)$.

\section{Discussion}

Plants used in traditional medicine are rich in physiologically active ingredients. There is a trend in recent pharmacological research to seek novel therapeutic agents on the basis of traditional Chinese medicine. Of the $80 \%$ of pharmaceuticals that are derived from plants, few are currently used as antimicrobial agents (24). LPS are ubiquitous and act as powerful stimulators of the immune system. Recently, a number of research groups have sought to develop treatments that are effective against LPS-mediated toxic effects by investigating the ingredients of traditional medicinal plants. The decoction of Forsythia was reported to elicit anti-inflammatory 

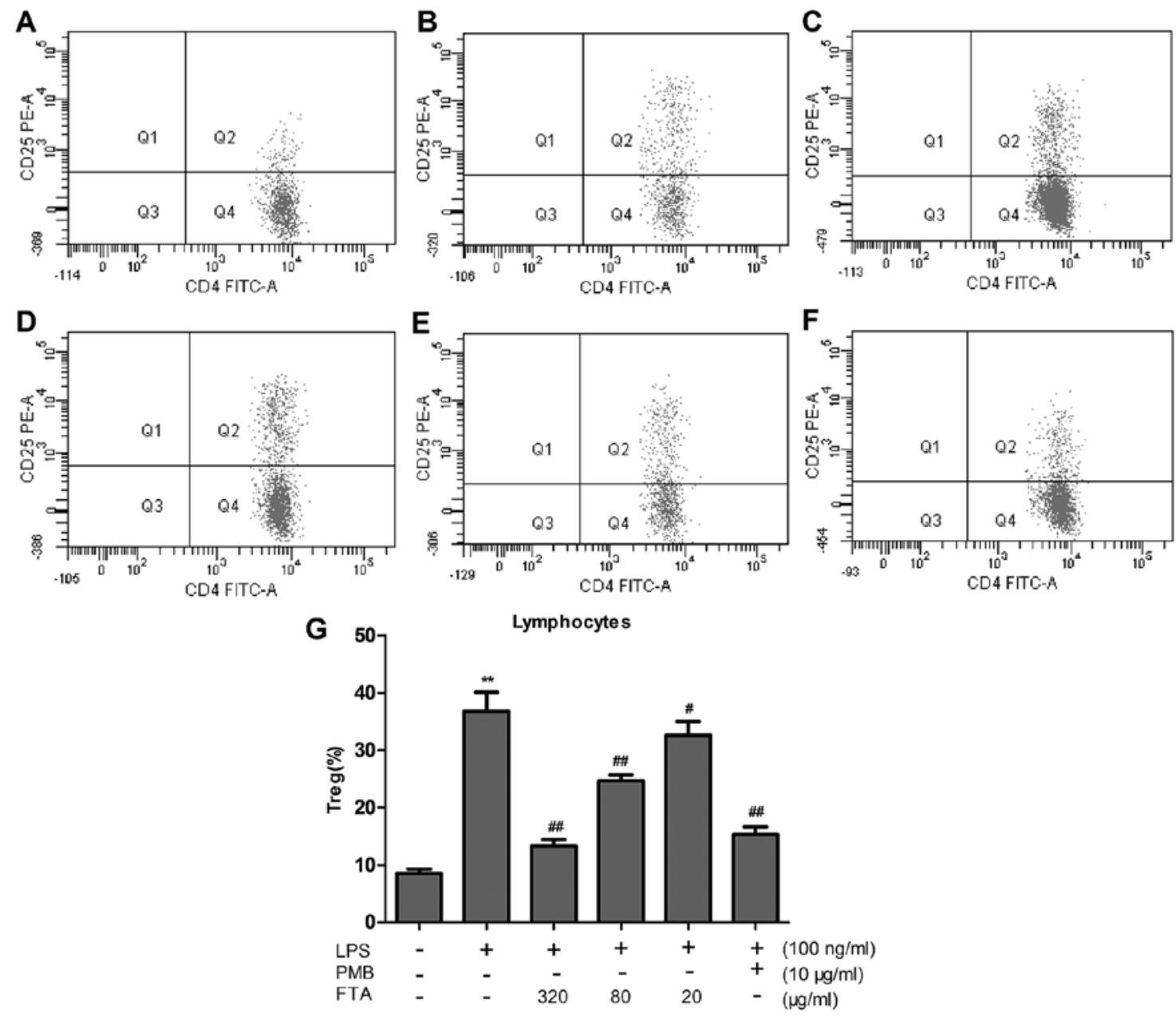

Figure 5. Forsythoside A (FTA) decreases the Treg percentage in a dose-dependent manner. Lymphocytes were stimulated with lipopolysaccharides (LPS) $(100 \mathrm{ng} / \mathrm{ml}, 48 \mathrm{~h})$ in the absence or presence of pretreatment with polymyxin B (PMB, $10 \mu \mathrm{g} / \mathrm{ml}, 2 \mathrm{~h})$ or FTA $(320,80 \mathrm{and} 20 \mu \mathrm{g} / \mathrm{ml}, 2 \mathrm{~h})$. The Treg percentage in total lymphocytes was quantified by flow cytometric analysis of (A) control-treated lymphocytes, (B) lymphocytes treated with LPS alone, (C) lymphocytes treated with LPS with FTA pretreatment $(320 \mu \mathrm{g} / \mathrm{ml})$, (D) lymphocytes treated with LPS with FTA pretreatment $(80 \mu \mathrm{g} / \mathrm{ml})$, and (E) lymphocytes treated with LPS with FTA pretreatment $(20 \mu \mathrm{g} / \mathrm{ml})$, (F) lymphocytes treated with LPS with pretreatment with PMB $(10 \mu \mathrm{g} / \mathrm{ml})$. (G) Histogram showing flow cytometry results. Values are expressed as the mean \pm SEM of three independent experiments. ${ }^{* *} \mathrm{P}<0.01$ vs. the control group; ${ }^{\# \#} \mathrm{P}<0.01$ and ${ }^{\#} \mathrm{P}<0.05$ vs. the LPS-treated group.

effects and, importantly, to ameliorate the adverse effects of LPS (25). In the present study, we demonstrated that FTA, the main antimicrobial constituent in Forsythia (26), exerts significant anti-endotoxin activity in LPS-treated mice and LPS-stimulated cells. The effect appears to be associated with the inhibition of the LPS-TLR4 signaling pathway and decreased number of Tregs.

PMB, a compound that exhibits strong affinity for LPS, is generally perceived to be an endotoxin antagonist. A low dose of PMB (50,000 U/day) was reported to decrease plasma endotoxin levels without eliciting any significant side effects (27). PMB-immobilized fiber column hemoperfusion has been used for treating septic shock, despite its potential to induce severe nephrotoxicity and neurotoxicity (28). Due to its anti-LPS efficacy, PMB was used as a positive control in our present study.

TLR, a receptor family closely related to the innate immunity, can recognize pathogen-associated molecular patterns (PAMP) and regulate innate and acquired immunity. TLR4 is the first TLR identified in humans, and is considered to be the most important receptor involved in the effects of
LPS. Tissue damage and infection lead to the recognition of bacterial lipoprotein and bacterial LPS by TLR4, initiating the signal transduction cascade and inducing the release of endogenous mediators, thereby stimulating the inflammatory response. The amplification cascade of inflammatory factors can aggravate infection and cause further tissue damage (29). Cell viability was significantly decreased compared to the vehicle-treated control group $(\mathrm{P}<0.05)$. Our findings, therefore, confirm the presence of adverse effects of LPS on cellular function. However, therapeutic agents have been shown to significantly reduce LPS-induced pathological changes in a dose-dependent manner. In our present study, we confirmed that FTA can ameliorate the effect of LPS on cell proliferation at the cellular level. Further study showed that levels of TLR4, MyD88, NF- $\kappa B$ and TNF- $\alpha$ protein in the FTA groups to be significantly and dose-dependently reduced $(\mathrm{P}<0.05)$, compared to those measured in the LPS groups. Through the effect involving several intracellular signaling molecules, LPS stimulates TLR4 signaling pathway downstream of the receptor, affecting both MyD88-dependent 

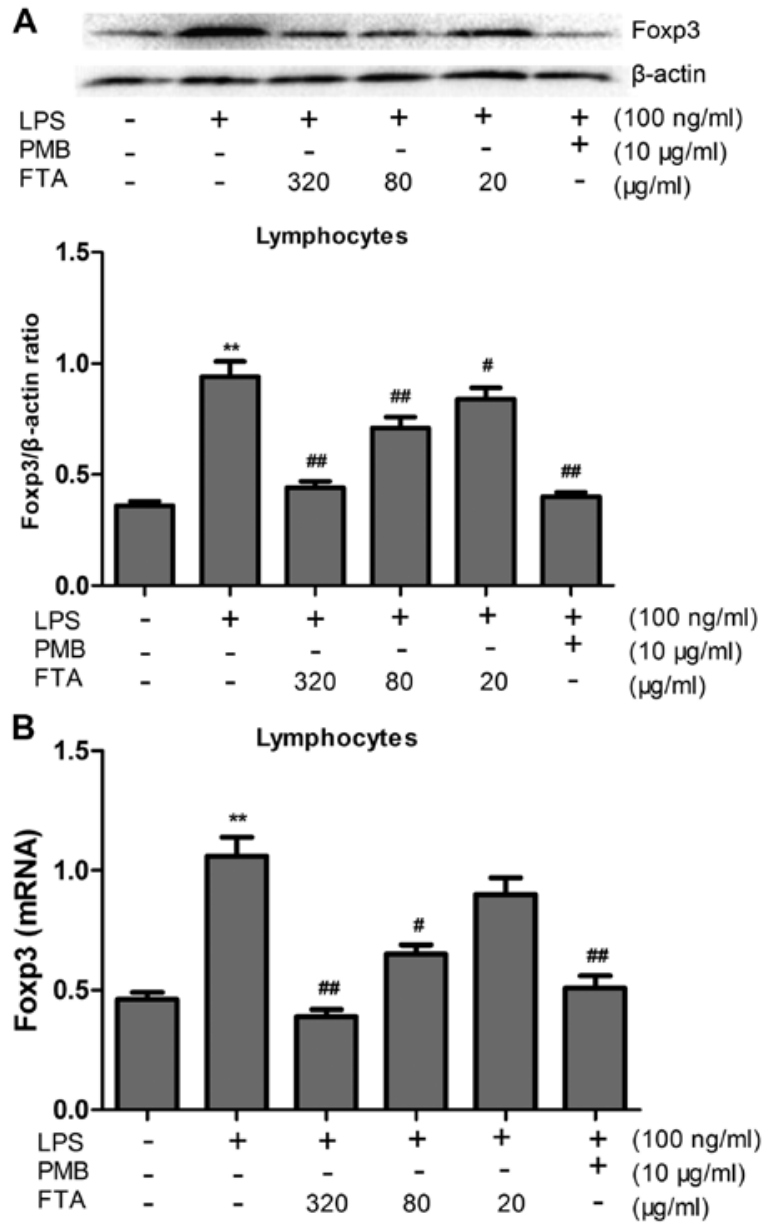

Figure 6. (A and B) Forsythoside A (FTA) decreases Foxp3 protein and mRNA expression in a dose-dependent manner. Lymphocytes were stimulated with lipopolysaccharides (LPS) $(100 \mathrm{ng} / \mathrm{ml}, 48 \mathrm{~h})$ in the absence or presence of pretreatment with polymyxin B (PMB, $10 \mu \mathrm{g} / \mathrm{ml}, 2 \mathrm{~h}$ ) or FTA (320, 80 and $20 \mu \mathrm{g} / \mathrm{ml}, 2 \mathrm{~h}$ ). Foxp3 protein level was assayed by western blot analysis. Foxp3 mRNA was assayed by quantitative real-time PCR. $\beta$-actin was used as a loading control. Values are expressed as the mean \pm SEM of three independent experiments. ${ }^{* *} \mathrm{P}<0.01$ vs. the control group; ${ }^{\# \#} \mathrm{P}<0.01$ and ${ }^{\text {"}} \mathrm{P}<0.05$ vs. the LPS-treated group.

and MyD88-independent (TRIF-dependent) pathways (30). Within the MyD88-dependent pathway, infection and cell damage activate signaling cascades involving inflammatory cytokines. Regardless of the signaling pathway, intracellular factors such as $\mathrm{NF}-\kappa \mathrm{B}$ and IRF3 are activated. NF- $\kappa \mathrm{B}$ is an important inducible transcription factor which can regulate the expression of cytokines such as TNF- $\alpha$, IL-6 and IL-8, along with other cytokines involved in the inflammatory and immune response, cell proliferation, tissue differentiation and apoptosis $(31,32)$. While TNF- $\alpha$ is important for the normal inflammatory response to infection, inappropriate or excessive production can be harmful (33). TNF- $\alpha$ acts through the TNF- $\alpha$ receptor I or TNF- $\alpha$ receptor II to induce apoptosis, regulate cell survival, or modulate inflammation (34). The successful use of TNF blockade in the management of chronic inflammatory diseases highlights the physiological role of TNF in sepsis (33). FTA may, therefore, inhibit inflammatory factors TNF- $\alpha$ and NF- $\kappa$ B through blockade of the LPS/TLR4 signaling pathway to elicit anti-endotoxin effects.
Caramalho et al previously reported that Tregs interact with LPS since they selectively express TLR4, thereby supporting their survival and proliferation, while also enhancing their immunosuppressive function (35). The present study showed that FTA suppresses LPS-mediated induction of the TLR4 pathway. Therefore, we propose that the protective effect of FTA may be elicited by regulation of Tregs.

Tregs elicit immunomodulatory effects and play a pivotal role in maintenance of the immune balance. $\mathrm{CD} 4^{+} \mathrm{CD} 25^{+}$ Tregs inhibit $\mathrm{CD}^{+} \mathrm{T}$ cell proliferation (36). In infection, Tregs mediate the responses of $\mathrm{T}$ cells to pathogens and their activation of inflammatory response to tissue damage (37). Our data showed a significantly lower survival rate of LPS-stimulated lymphocytes, compared to the control group, while the relative presence of Tregs in culture was significantly higher $(\mathrm{P}<0.01)$. These findings indicate that the immunosuppressive ability of LPS-stimulated lymphocytes is inhibited, and confirm that LPS adversely affects Treg function. The effects of LPS may be related to the excessive activation of Tregs, resulting in inhibition of $\mathrm{CD} 4^{+} \mathrm{CD} 25^{-}$cell proliferation. Experiments evaluating the effects of FTA intervention showed that FTA can significantly increase the survival rate of LPS-stimulated lymphocytes and decrease the relative presence of Tregs in a dose-dependent manner $(\mathrm{P}<0.05)$. In comparing cells treated with a high dose of FTA with the control group, no obvious difference was found ( $\mathrm{P}>0.05)$, suggesting that the cytoprotective effect of FTA may involve the inhibition of Treg activation to correct the LPS-induced inhibition of cell immunity. Foxp3 is widely recognized to act as a master switch and transcription factor for Treg development and function (38), and is the most specific biomarker for Treg activation (39). Deletion of the Foxp3 gene was found to eliminate the immunosuppressive activity of $\mathrm{CD} 4^{+} \mathrm{CD} 25^{+}$Tregs, while the ectopic expression of Foxp3 in CD25- Tregs conferred immunosuppressive activity to the cells (40). Human Foxp3 gene mutation has been linked with immunological dysfunction, inflammatory bowel disease (IBD), X-linked syndrome and allergic dermatitis (41). In light of the significance of Foxp3, we evaluated the expression of this protein in our experiments. In LPS-stimulated groups, Foxp3 expression was markedly increased, with this increase being significantly suppressed in FTA groups. These findings indicate that FTA may inhibit Treg activity by inhibiting Foxp3. IL-10 and TGF- $\beta 1$ are involved in the regulation of Foxp 3 expression and the secretion of IL- 10 and TGF- $\beta 1$ is one of the ways in which Tregs suppress antigen-driven response of $\mathrm{CD} 4^{+} \mathrm{CD} 25^{-}$cells (42-45). The two aspects contribute to the immunosuppressive activity of $\mathrm{CD} 4^{+} \mathrm{CD} 25^{+}$Tregs. In this study, FTA intervention could significantly inhibit IL-10 and TGF- $\beta 1$, which may be one of the mechanisms underlying the observed downregulation of Foxp3.

In conclusion, we validated the therapeutic potential of FTA for endotoxin-induced diseases. Furthermore, we identified the blockade of the LPS/TLR4 signaling pathway and inhibition of Tregs as putative mechanisms underlying the protective action of FTA. While this study demonstrates the potential for clinical efficacy of FTA, it should be noted that the clinical effects may differ from our experimental results due to the involvement of bacteria other than the LPS-producing species in the clinical setting. Further studies are, therefore, warranted to extend our experimental findings into the clinical setting. 


\section{Acknowledgements}

The study was supported by the National Natural Science Foundation, China (no. 81060354) and a grant from the Education Department of Jiangxi Province of China (no. GJJ11338). This manuscript has been edited and proofread by Editage.

\section{References}

1. Alexander C and Rietschel ET: Bacterial lipopolysaccharides and innate immunity. J Endotoxin Res 7: 167-202, 2001.

2. Unger RE, Peters K, Sartoris A, Freese $C$ and Kirkpatrick CJ: Human endothelial cell-based assay for endotoxin as sensitive as the conventional Limulus Amebocyte Lysate assay. Biomaterials 35: 3180-3187, 2014

3. Beutler B and Rietschel ET: Innate immune sensing and its roots: The story of endotoxin. Nat Rev Immunol 3: 169-176, 2003.

4. Bone RC, Balk RA, Cerra FB, Dellinger RP, Fein AM Knaus WA, Schein RM and Sibbald WJ; The ACCP/SCCM Consensus Conference Committee. American College of Chest Physicians/Society of Critical Care Medicine: Definitions for sepsis and organ failure and guidelines for the use of innovative therapies in sepsis. Chest 101: 1644-1655, 1992.

5. Yamamoto M, Sato S, Hemmi H, Sanjo H, Uematsu S, Kaisho T, Hoshino K, Takeuchi O, Kobayashi M, Fujita T, et al: Essential role for TIRAP in activation of the signalling cascade shared by TLR2 and TLR4. Nature 420: 324-329, 2002.

6. Li X and Qin J: Modulation of Toll-interleukin 1 receptor mediated signaling. J Mol Med (Berl) 83: 258-266, 2005.

7. Miyake K: Endotoxin recognition molecules, Toll-like receptor 4-MD-2. Semin Immunol 16: 11-16, 2004.

8. Medzhitov R, Preston-Hurlburt P and Janeway CA Jr: A human homologue of the Drosophila Toll protein signals activation of adaptive immunity. Nature 388: 394-397, 1997.

9. Moynagh PN: TLR signalling and activation of IRFs: Revisiting old friends from the NF-kappaB pathway. Trends Immunol 26 : 469-476, 2005

10. Huo M, Cui X, Xue J, Chi G, Gao R, Deng X, Guan S, Wei J, Soromou LW, Feng H, et al: Anti-inflammatory effects of linalool in RAW264.7 macrophages and lipopolysaccharide-induced lung injury model. J Surg Res 180: e47-e54, 2013.

11. Craig R, Larkin A, Mingo AM, Thuerauf DJ, Andrews C, McDonough PM and Glembotski CC: p38 MAPK and NF-kappaB collaborate to induce interleukin-6 gene expression and release. Evidence for a cytoprotective autocrine signaling pathway in a cardiac myocyte model system. J Biol Chem 275: 23814-23824, 2000

12. Sakaguchi S, Yamaguchi T, Nomura T and Ono M: Regulatory T cells and immune tolerance. Cell 133: 775-787, 2008

13. Chen W, Jin W, Hardegen N, Lei KJ, Li L, Marinos N, McGrady G and Wahl SM: Conversion of peripheral $\mathrm{CD} 4{ }^{+} \mathrm{CD} 25^{-}$naive $\mathrm{T}$ cells to $\mathrm{CD} 4{ }^{+} \mathrm{CD} 25^{+}$regulatory $\mathrm{T}$ cells by TGF-beta induction of transcription factor Foxp3. J Exp Med 198: 1875-1886, 2003.

14. Shevach EM: Mechanisms of foxp $3^{+} \mathrm{T}$ regulatory cell-mediated suppression. Immunity 30: 636-645, 2009.

15. Klayman DL: Qinghaosu (artemisinin): An antimalarial drug from China. Science 228: 1049-1055, 1985.

16. Luo J, Xu H and Chen K: Systematic review of compound danshen dropping pill: a chinese patent medicine for acute myocardial infarction. Evid Based Complement Alternat Med 2013: 808076, 2013.

17. Zhu T, Wang DX, Zhang W, Liao XQ, Guan X, Bo H, Sun JY, Huang NW, He J, Zhang YK, et al: Andrographolide protects against LPS-induced acute lung injury by inactivation of NF- $\mathrm{NB}$ PLoS One 8: e56407, 2013.

18. Yu PJ, Li JR, Zhu ZG, Kong HY, Jin H, Zhang JY, Tian YX, $\mathrm{Li} \mathrm{ZH,} \mathrm{Wu} \mathrm{XY,} \mathrm{Zhang} \mathrm{JJ,} \mathrm{et} \mathrm{al:} \mathrm{Praeruptorin} \mathrm{D} \mathrm{and} \mathrm{E} \mathrm{attenuate}$ lipopolysaccharide/hydrochloric acid induced acute lung injury in mice. Eur J Pharmacol 710: 39-48, 2013

19. Li T, Zhang J, Feng J, Li Q, Wu L, Ye Q, Sun J, Lin Y, Zhang M, Huang R, et al: Resveratrol reduces acute lung injury in a LPS induced sepsis mouse model via activation of Sirt1. Mol Med Rep 7: 1889-1895, 2013

20. Shi Y, Zhang B, Chen XJ, Xu DQ, Wang YX, Dong HY, Ma SR, Sun RH, Hui YP and Li ZC: Osthole protects lipopolysaccharideinduced acute lung injury in mice by preventing downregulation of angiotensin-converting enzyme 2. Eur J Pharm Sci 48 819-824, 2013
21. Liu WB, Li DP, Zhang GL, Sun L and Zhang NS: Study progress of the pharmacological activity of forsythoside A. Chin Anim Husbandry Vet Med 38: 236-238, 2011 (In Chinese).

22. Lu S, Chen SN, Guan JY and Shen H: Effects of forsythoside on cell functions of raw264.7 stimulated by LPS. Zhongguo Nongxue Tongbao 28: 58-62, 2012 (In Chinese)

23. Liu H, Sidiropoulos P, Song G, Pagliari LJ, Birrer MJ, Stein B, Anrather J and Pope RM: TNF-alpha gene expression in macrophages: Regulation by NF-kappa B is independent of c-Jun or C/EBP beta. J Immunol 164: 4277-4285, 2000.

24. Perumal Samy R and Gopalakrishnakone P: Therapeutic potential of plants as anti-microbials for drug discovery. Evid Based Complement Alternat Med 7: 283-294, 2010.

25. Hu JY, Lei L, Yu Y and Deng WL: Studies on the anti-inflammatory and antipyretic effect of forsythia. Pharmocol Clin Chin Mater Med 23: 51-52, 2007.

26. Qin Z, Xu J and Zhang LJ: Studies on the anti-bacteria effect of fructus forsythia and folium forsythia in vitro. Food Eng 2: 49-52, 2013.

27. Shao Y, Wang X, Cai SX, Gao W and Wu X: Hemodynamic effect of polymyxin B sulfate on rats with endotoxemia. Chongqing Univ (Natur. Sci. Ed.) 25: 84-86, 2002.

28. Mitaka $\mathrm{C}$ and Tomita M: Polymyxin B-immobilized fiber column hemoperfusion therapy for septic shock. Shock 36: 332-338, 2011.

29. Figueiredo RT, Bittencourt VCB, Lopes LCL, Sassaki G and Barreto-Bergter E: Toll-like receptors (TLR2 and TLR4) recognize polysaccharides of Pseudallescheria boydii cell wall. Carbohydr Res 356: 260-264, 2012.

30. Lu YC, Yeh WC and Ohashi PS: LPS/TLR4 signal transduction pathway. Cytokine 42: 145-151, 2008.

31. Lee JK, Kim SY, Kim YS, Lee WH, Hwang DH and Lee JY: Suppression of the TRIF-dependent signaling pathway of Toll-like receptors by luteolin. Biochem Pharmacol 77: 1391-1400, 2009.

32. Słotwiński R, Słotwińska S, Kedziora S and Bałan BJ: Innate immunity signaling pathways: Links between immunonutrition and responses to sepsis. Arch Immunol Ther Exp (Warsz) 59: 139-150, 2011.

33. Bradley JR: TNF-mediated inflammatory disease. J Pathol 214: 149-160, 2008

34. Wu Y and Zhou BP: TNF-alpha/NF-kappaB/Snail pathway in cancer cell migration and invasion. Br J Cancer 102: 639-644, 2010.

35. Caramalho I, Lopes-Carvalho T, Ostler D, Zelenay S, Haury M and Demengeot J: Regulatory T cells selectively express toll-like receptors and are activated by lipopolysaccharide. J Exp Med 197: 403-411, 2003.

36. Kosmaczewska A, Ciszak L, Potoczek S and Frydecka I: The significance of Treg cells in defective tumor immunity. Arch Immunol Ther Exp (Warsz) 56: 181-191, 2008.

37. Nakamura K, Kitani A and Strober W: Cell contact-dependent immunosuppression by $\mathrm{CD} 4(+) \mathrm{CD} 25(+)$ regulatory $\mathrm{T}$ cells is mediated by cell surface-bound transforming growth factor beta. J Exp Med 194: 629-644, 2001.

38. Fontenot JD, Gavin MA and Rudensky AY: Foxp3 programs the development and function of $\mathrm{CD} 4{ }^{+} \mathrm{CD} 25^{+}$regulatory T cells. Nat Immunol 4: 330-336, 2003

39. Lal G, Zhang N, van der Touw W, Ding Y, Ju W, Bottinger EP, Reid SP, Levy DE and Bromberg JS: Epigenetic regulation of Foxp3 expression in regulatory T cells by DNA methylation. J Immunol 182: 259-273, 2009.

40. Fontenot JD and Rudensky AY: A well adapted regulatory contrivance: Regulatory T cell development and the forkhead family transcription factor Foxp3. Nat Immunol 6: 331-337, 2005.

41. Wildin RS and Freitas A: IPEX and FOXP3: Clinical and research perspectives. J Autoimmun 25 (Suppl): 56-62, 2005.

42. Murai M, Turovskaya O, Kim G, Madan R, Karp CL, Cheroutre H and Kronenberg M: Interleukin 10 acts on regulatory $\mathrm{T}$ cells to maintain expression of the transcription factor Foxp3 and suppressive function in mice with colitis. Nat Immunol 10: 1178-1184, 2009.

43. Kawamoto K, Pahuja A, Hering BJ and Bansal-Pakala P: Transforming growth factor beta 1 (TGF-beta1) and rapamycin synergize to effectively suppress human $\mathrm{T}$ cell responses via upregulation of FoxP3 ${ }^{+}$Tregs. Transpl Immunol 23: 28-33, 2010.

44. Yan B and Da WM: $C D 4^{+} \mathrm{CD} 25^{+}$regulatory T cells and their function in graft-versus-host disease - review. Zhongguo Shi Yan Xue Ye Xue Za Zhi 14: 408-412, 2006 (In Chinese).

45. Khazaie $\mathrm{K}$ and von Boehmer $\mathrm{H}$ : The impact of $\mathrm{CD} 4^{+} \mathrm{CD} 25^{+}$Treg on tumor specific $\mathrm{CD}^{+} \mathrm{T}$ cell cytotoxicity and cancer. Semin Cancer Biol 16: 124-136, 2006. 